\title{
A randomized trial of blended first aid education for the public
}

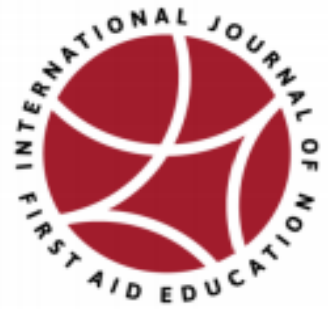

Emily Oliver, Mark Forsyth, Daniel Colebourn, Ellen Gordon, Hannah Taylor, and Joe Mulligan

First aid educators are increasingly experimenting with blending learning modalities, combining asynchronous internet based (e-learning) and traditional instructor led (face-to-face). This study seeks to validate the effectiveness of using e-learning followed by face-to-face learning in first aid education to improve laypersons' knowledge, confidence, and willingness, compared to face-to-face only learning.

Method: 128 non-healthcare adult volunteers (laypeople) were randomly assigned to either a face-to-face (control, $n=58$ ) or a blended (experimental, $n=70$ ) British Red Cross Everyday First Aid course. The effectiveness of learning was measured through pre- and post-learning evaluation forms using 0-10 Likert scales and questions on first aid knowledge for both face-to-face and blended groups, and additionally, post-online (blended learners only).

Results: We found comparable results between face-to-face and blended learning for improving learner knowledge of first aid. Blended learners were found to have increased confidence and willingness than face-toface learners. In the blended cohort, knowledge appears to increase most during the online phase, but this is not mirrored for confidence or willingness.

Discussion: Blended learning appears to be comparable to face-to-face only learning for first aid education for learner outcomes of knowledge, and superior for increasing confidence and willingness in the study sample. Providing an alternative learning modality can allow more flexibility for those providing and those joining first aid courses. An implication of this study is the potential for educators to offer different learning opportunities according to learner preference.

First aid educators are increasingly experimenting with and implementing blending learning. However, we were unable to find studies that validated this approach in lay public first aid course outcomes. As more and more people have access to online content, it appeared timely to study a blended approach for feasibility compared to face-to-face courses in an effort to better understand its value and costs.

The integration of "digital learning objects" (ChumleyJones \& Dobbie, \& Alford, 2002) within learning environments has been firmly established as viable pedagogical practice across medical education, including first aid training. This approach involves a range of digital learning interventions, described as "elearning" (Perkins et al., 2010, 2012; Thorne et al., 2015), "E-Teaching” and "distance learning" (Golchaia et al., 2012) or "computer aided instruction/learning" (Hudson, 2004; Golchaia et al., 2012). Digital learning objects is a catch-all term for these learning pathways which utilise web-based media, animation, videos, mobile applications, gamification, or virtual realities. Defined by Johnson (2003) and Smith (2004) and later applied to the field of medical education (Ruiz et al., 2006), a digital learning object describes any digital 
materials grouped and structured to provide medical training.

When it comes to utilising digital learning objects, how we think of blended, embedded, or integrated educational praxis varies greatly. For Golchai et al. (2012), digitally blended learning environments increase flexibility, access, personalization, efficiency, learner motivation, participant interactivity and cognitive effectiveness. Hudson (2004), citing Glaser (1991), has suggested computer-aided learners are active learners, and competence (rather than rote learning) is fostered. This develops a learner's capacity to 'engage in the process of building and testing their own mental models (Modell, 1996). Digital learning objects can be explored, contemplated, deconstructed and reconstructed. Thorne et al. (2015) suggest blended learning can improve 'cost-effectiveness, decreased instructor burden and improved standardisation of course material'.

Practically, notable potential limitations of blended learning exist, including difficulty in validating learner assessment in/from digital experiences (Taplin \& McConigley, 2015). Additionally, practicalities, such as intermittent internet access leading to the loss of work can inhibit a learner's progress (Taplin \& McConigley, 2015). Indeed, many of the benefits that follow from embedding digital objects into learning environments-versatility, efficiency, personalization, competence and self-guidance-could translate computer illiteracy into a learning disadvantage (Perkins, et al., 2012).

'Blended learning' in the context of this study describes a sequenced mixture of digital learning objects presented online (e-learning) followed by face-to-face facilitated learning. We chose this because digital learning objects can create interaction and can be receptive to the input of a learner (Johnson, 2003; Smith, 2004) like a traditional instructor/ educator. We sought to provide a holistic experience for learners where content was shared across the two modalities (Ruiz et al., 2006; Walsh, 2005; Ellio, 2014), thus providing expanded opportunities for:

- reinforcement of messages to minimize knowledge and skill decay through learner and/or educator-controlled repetition and varied approaches to tasks (Dikshit et al., 2013; Einspruch et al., 2007; Mpotos et al., 2013; De Vries et al., 2010)

- providing appropriate evidence-based clinical knowledge framed for different levels or different learner needs, and

- developing confidence and willingness to act in an emergency using multi-media approaches (Oliver et al., 2013).

These elements were considered as a means to represent the intention behind 'educational efficiency' which is one of the multiplicands (along with medical science and local implementation) necessary for survival in the Utstein Formula for Survival (Søreide et al, 2013). They also point towards a potential for blended learning within the Chain of Survival Behaviour (Pellegrino et al, 2017), using different learning modalities to support, emphasise and reiterate learning through the different domains (prevent and prepare, recognise, provide or access help, recover or receive ongoing care). We used these educational models to anchor our research questions:

1) Does a blended learning approach improve first aid knowledge compared to a face-to-face only learning experience?

2) Does a blended learning approach improve layperson confidence to act in a first aid emergency compared to a face-to-face only learning experience?

3) Does a blended learning approach improve layperson willingness to act in a first aid emergency compared to a face-to-face only learning experience?

\section{Methods}

Our study employed a random assignment to face-toface or blended intervention. We offered employees at locations of Philips ${ }^{\mathrm{TM}}$ a free first aid course for up to 200 volunteers. Courses occurred during work hours and at work. Employees who volunteered to participate were randomly allocated to a face-to-face or blended group. No volunteers were excluded from the study. Volunteers were blinded to the fact that the courses 
were different but aware that they were joining a quality improvement project. Human subject approval was not sought since this program was already a standard for Philips ${ }^{\mathrm{TM}}$ but offered in a different modality, for the purpose of quality improvement. Participants were informed at registration and during the face-to-face element that they were part of the project, were free to withdraw at any time without penalty, and not obliged to complete the evaluation at any stage.

Knowledge, self-reported confidence, and selfreported willingness to act in first aid emergencies data were collected through pre-learning and post-learning evaluation forms relating to the topics covered (provided as supplemental files). Knowledge was evaluated using scenario-based questions for each topic covered. Questions were conceived by the researchers and based closely on existing learner feedback forms used by the British Red Cross, and existing learning outcomes for each topic. Free-text answers were assessed by the research team from open-ended actionto-take questions.

For example, the question for bleeding was:

Someone has broken a glass and cut their hand badly. The wound is clean with no glass stuck in it. Apart from comforting the person or calling for help, what do you think is the most important first aid action to help the person in this situation?

Learner responses to the open-ended knowledge questions on the forms were marked according to a marking scheme decided by the lead researcher in consultation with colleagues. Answers were marked as a fail, fail with extra, or pass. Fail was given a score of 0 , fail with extra was given a score of 0.5 and pass given a score of 1 . A fail with extra was awarded if the learner responded with a first aid action but failed to provide the primary first aid action as advised during training. For example, the question above could be answered and scored as follows:

- Answer "Reassure the person": Fail=0 mark. The question states "...apart from comforting the person..."

- Answer "Bandage the cut": Fail with extra $=0.5$ marks. This is a first aid action, but not the primary one.
- Answer "Apply pressure": Pass =1 mark. This is the most urgent and effective action.

A total score was calculated for each learner at each stage of evaluation. Knowledge was rated out of a possible total of 18 marks.

Learners' self-perception of confidence was captured using self-rated 0-10 Likert scales for each skill (see supplemental files) and overall. Similarly, overall willingness to act in an emergency used a self-rated 0 10 Likert scale. Only gender demographics were collected due to time constraints. We collected data at three time points, using the same evaluation form:

- $\quad \mathrm{T} 1=$ pre-learning

- $\mathrm{T} 2=$ post e-learning (experimental group only)

- $\mathrm{T} 3=$ post-learning

\section{Data Analysis}

Learner responses to the open-ended knowledge questions on the forms were marked out of a total score of 18 as described above. A total score was calculated by adding the individual question scores together. As approximately $5 \%$ of responses were unanswered or illegible, a final composite score was calculated by dividing the total score by the number of answered and legible responses, expressed as a percentage. One participant who did not attempt any questions on the final test was excluded from this analysis.

We applied tests for normality for baseline knowledge, confidence and willingness scores, and calculated median and interquartile ranges for pre and post learning for each outcome measure. We used nonparametric tests (Mann-Whitney U) for significance using SPSS software (IBM SPSS Statistics, v24). We compared knowledge and confidence at different time points to see where the change (if any) occurred in the blended learning approach.

\section{Learning content}

All curriculum content was drawn from the British Red Cross (BRC) Everyday approach. The Everyday approach reflects the International Federation of Red Cross and Red Crescent Societies' (IFRC) 2016 first aid guidelines and educational implementation 
recommendations (IFRC, 2016). The curriculum included: Stroke, Heart Attack, Allergic Reaction, Diabetic Emergency, Seizure, Head Injury; and Bleeding, Burn, Strains/Sprains, Choking, Broken Bones, Unconscious Not Breathing, Unconscious and Breathing (British Red Cross, 2014). The Everyday approach also includes activities around the qualities of "being a helper" (Oliver et al., 2013).

Face-to-face group learners attended one four-hour face-to-face first aid training session using the following structure:

- Introduction to the course by the educator, including briefing on the 'research' element and opportunity to withdraw (from the course and/or the evaluation)

- Completion of T1 pre-learning user evaluation form (paper form)

- Training with the educator in 13 first aid skills and additional helping behaviour activities, including a helping behaviour video

- Completion of T3 post-learning user evaluation form (paper form).

There was one educator for each course and numbers of learners ranged from seven to 13 .
Blended group learners were given access to the elearning tool, through a link to the British Red Cross first aid learning website, in an email sent by the employer one week before they attended a 2.5-hour face-to-face training session. The link took them to a closed learning platform which included a mixture of text, video, images, animations, and interactive elements for learners covering the 13 first aid skills and confidence-building activities and messages. The approximate time required for exploring the e-learning tool was designed to be 1.5 hours, and this was explained in the email. The e-learning tool steered the learner through the following stages:

- Introduction to the course (online information) explaining what they would be doing and what the course would cover (including option to withdraw)

- Completion of digital version of the T1 prelearning user evaluation form

- Work through the e-learning independently including a quiz to test their learning (this did not form part of the evaluation).

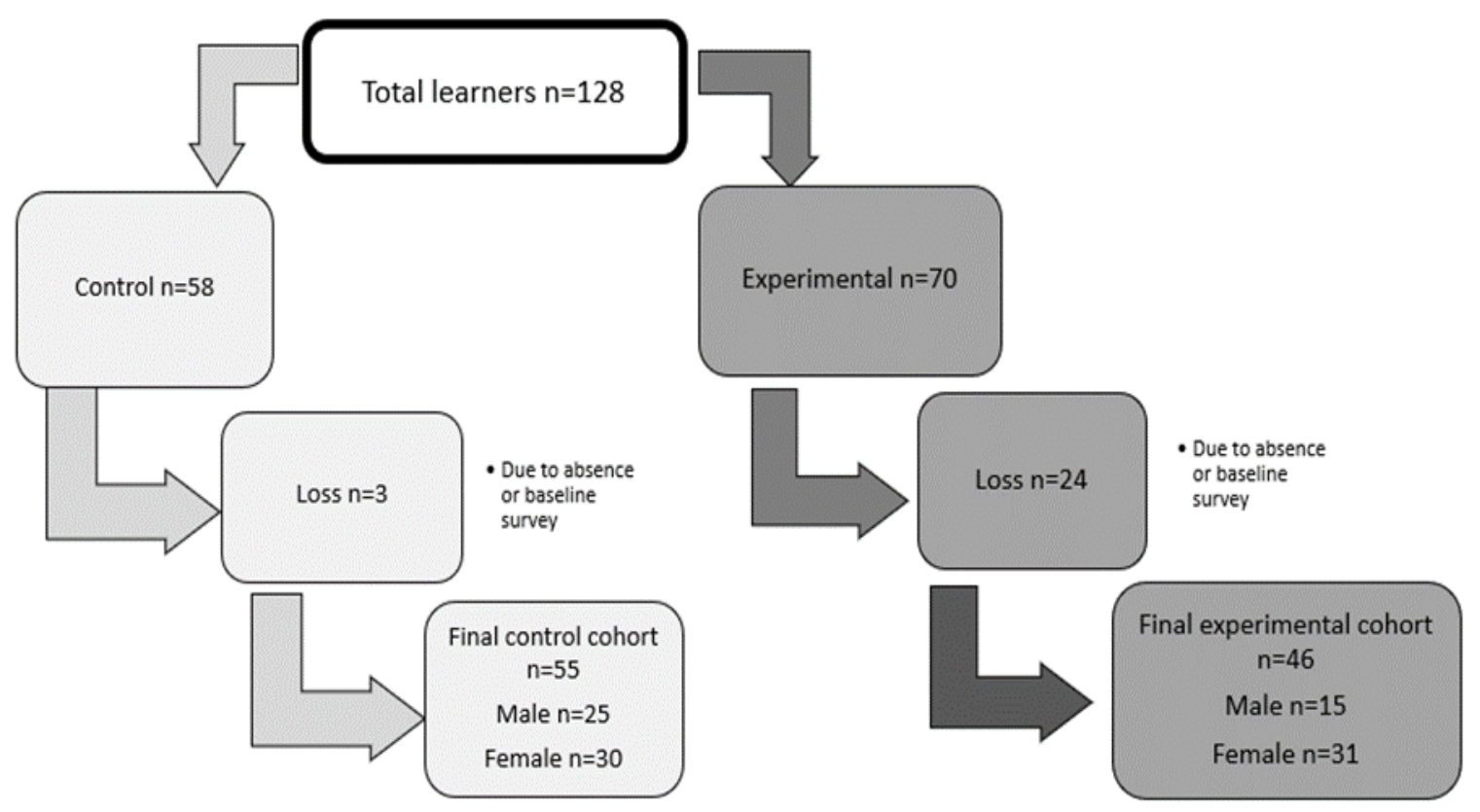

Figure 1: Participant flow and gender split 
Following this, blended learners:

- Attended face-to-face first aid training session lasting 2.5 hours at which they completed T2 post e-learning assessment

- Completed T3 post-learning user evaluation form.

There was one educator per course and the number of learners ranged from four to ten.

Both groups participated in activities on being a helper but through different formats. The blended group experienced an online lesson with a video and content for them to read about helping behaviour. The face-toface group watched the same video in the classroom. Four experienced BRC educators were allotted to courses based on availability and location. Each prepared for the lessons of both groups for consistency, therefore blinding of educators was not possible. One educator delivered two face-to-face and three blended courses. A second educator delivered three face to face; a third delivered three blended; and the fourth educator delivered one face to face course. It was not possible to distribute educators evenly across face-to-face and blended courses due to logistics and geography.

Pilot courses (face-to-face $n=32$, and blended $n=18$ ) were run at each of the three locations before the main courses occurred. This allowed for testing of logistics and evaluation methods. Minor logistical challenges were ironed out at this time, but no changes were required for evaluation methods following the pilots.

\section{Participants}

This population of workplace office-based employees had equal opportunity to participate and were expected to have online learning literacy, as the company utilizes its own e-learning platform. One-hundred-twenty-eight volunteers were randomly assigned to a face-to-face course $(n=58)$ or blended course $(n=70)$. Discrepancy in allocation occurred because course assignments varied between three locations - one location only had enough volunteers for one course. Numbers of participants on each course were also affected by availability on the day. Courses occurred in Philips ${ }^{\mathrm{TM}}$ offices across three locations, with no expected difference in workforce capabilities. In total, 101 learners (55 face-to-face and 46 blended) attended the courses as planned and completed pre learning evaluations. 100 learners returned post learning evaluations for analysis. Figure 1 explains the participant flow including gender split for each cohort.

\section{Results}

Tests for normality and the visual inspection of histograms in knowledge, self-reported confidence, and willingness identified non-normal distributions and therefore unsuited to analysis using parametric procedures.

\section{Knowledge}

The face-to-face group was found to have a higher mean rank (face-to-face $=52.84$, blended $=47.75$ ) for knowledge. Mann-Whitney $U$ analysis found the difference between the two groups not to be statistically significant $(\mathrm{U}=1115.5, \mathrm{df}=1, \mathrm{p}=0.378)$. Table 1 provides the median percentage and interquartile range of knowledge scores (out of 18) to show change between T1 and T3. Appendix 1 provides the percentage change in knowledge by skill pre to post learning. We found no statistical significance $(\mathrm{p} \leq 0.05)$ between face to face and blended learning for 11 out of 13 skills. For 'allergic reaction' we found face to face to be statistically more effective $(\mathrm{p}=0.033)$, and for 'burns' we found blended learning to be more effective in building knowledge $(\mathrm{p}=0.029)$.

Table 1: Change in knowledge by percentage

\begin{tabular}{lcc}
\hline & $\begin{array}{c}\text { T1 } \\
\text { Median } \\
\text { (IQ Range) }\end{array}$ & $\begin{array}{c}\text { T3 } \\
\text { (IQ Range) }\end{array}$ \\
\hline Face to face & $52.8 \%(19.9)$ & $94.3 \%(13.9)$ \\
Blended & $52.8 \%(22.3)$ & $90.3 \%(9.7)$ \\
\hline
\end{tabular}

\section{Confidence}

The blended group was found to have a higher mean rank (face-to-face $=44.77$, blended $=57.23$ ) for general confidence at T3. A Mann-Whitney $U$ analysis identified the difference between the two groups to be statistically significant $(\mathrm{U}=932.5, \mathrm{df}=1, \mathrm{p}=0.028)$. See 
Table 2 for medians and interquartile ranges for selfreported confidence between groups at baseline and endpoint. Appendix 2 provides the change in median for confidence by skill pre to post learning. We found statistical significance $(p \leq 0.05)$ for nine out of 13 skills in favour of blended learning.

Table 2: Change in Self-reported general confidence score

\begin{tabular}{lcc}
\hline & $\begin{array}{c}\text { T1 } \\
\text { Median } \\
\text { (IQ Range) }\end{array}$ & $\begin{array}{c}\text { T3 } \\
\text { Median } \\
\text { (IQ Range) }\end{array}$ \\
\hline Face to face & $3.0(4.0)$ & $8.0(2.0)$ \\
Blended & $3.0(4.0)$ & $9.0(1.0)$ \\
\hline
\end{tabular}

\section{Willingness}

The blended group was found to have a higher mean rank (face-to-face $=45.05$, blended $=56.90$ ) at T3 . Mann-Whitney $U$ analysis found the difference between the two groups to be statistically significant $(\mathrm{U}=947.5, \mathrm{df}=1, \mathrm{p}=0.036$ ). See Table 3 for medians and interquartile ranges between $\mathrm{T} 1$ and $\mathrm{T} 3$ for willingness. Learners were not asked to rate willingness against each skill.

Table 3: Change in Self-reported willingness

\begin{tabular}{lcc}
\hline & $\begin{array}{c}\text { T1 } \\
\text { Median } \\
\text { (IQ Range) }\end{array}$ & $\begin{array}{c}\text { T3 } \\
\text { (IQ Range) }\end{array}$ \\
\hline Face to face & $4.0(6.0)$ & $8.0(2.0)$ \\
Blended & $5.0(5.0)$ & $9.0(2.0)$ \\
\hline
\end{tabular}

\section{Learning outcomes at different timepoints}

Figure 2 shows diagrammatically the medians for knowledge, confidence, and willingness at pre-learning (T1), post-e-learning (T2), and post-learning (T3). This provides some perspective on where blended elements had different effects.
Figure 2a: Knowledge over time

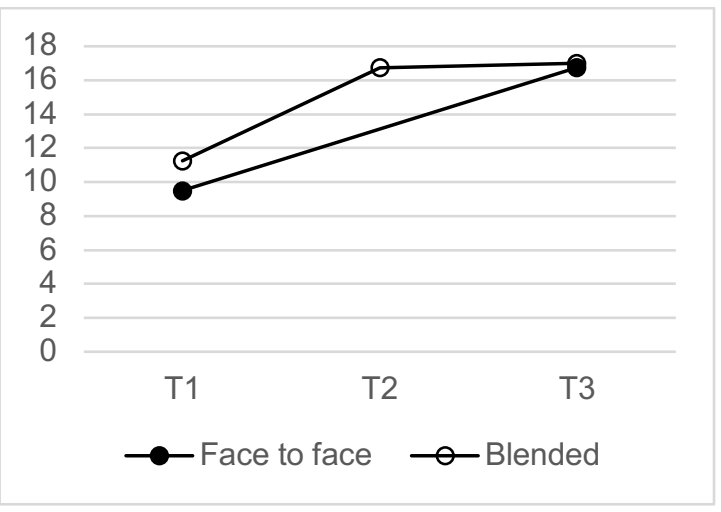

Figure 2b: Confidence over time

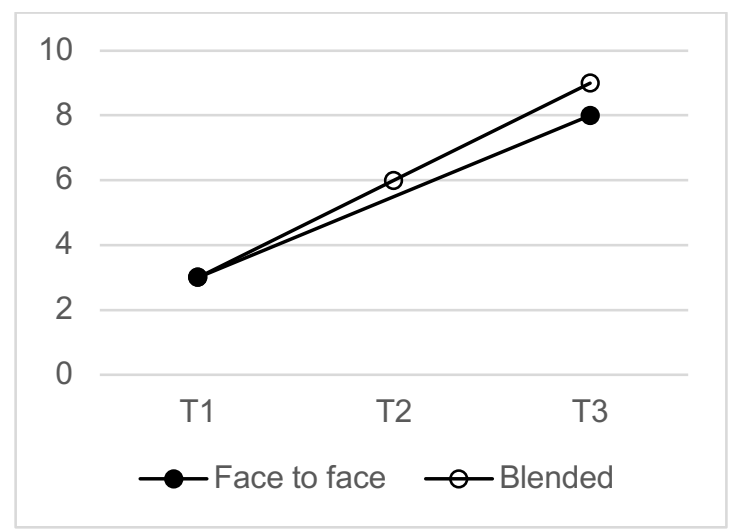

Figure 2c: Willingness over time

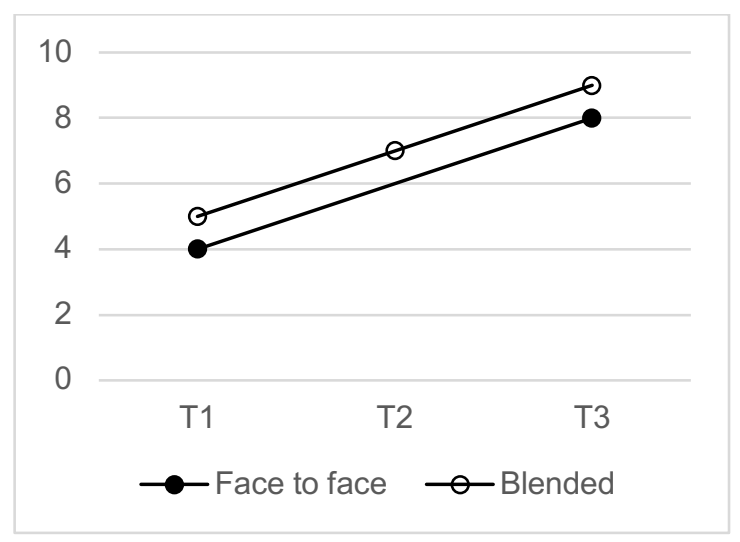

\section{Discussion}

In this study, laypersons had a statistically increased level of self-reported confidence and willingness to respond to first aid emergencies with a pre-course elearning experience followed by a face-to-face education session. There are multiple reasons for exploring this learning style in layperson first aid 
education. As described in the literature review, the limited previous studies available tend to focus on the ability of learners to perform CPR and conclude that digital media is effective for teaching CPR. This study concurs with these results and expands the potential to other first aid topics.

From a pedagogical perspective, our study did not aim to test the adequacy of the e-learning element as a stand-alone learning tool. Rather, this study contributes to the evidence that blended learning can offer a reasonable alternative and potentially increase confidence and willingness from traditional face-toface courses. In our study, blended learners appeared to gain knowledge, confidence and willingness through the e-learning component, and confidence and willingness were boosted through the face-to-face component, indicating that the face to face time with learners is important for building confidence and willingness.

We did not systematically assess the role of the educator in being able to offer reassurance or other psychological elements during face to face time with either cohort. However, since we saw an increase in confidence in the blended approach, we suggest that this was likely due to reinforcement of knowledge that learners had gained from the online element. We did not have the means of determining why willingness increased significantly in the blended over the face to face course, but this could also be due to the reinforcement of learning which the blended offer affords. As the content of both courses was identical in terms of skills presented, it is not surprising that knowledge attainment is comparable between the two approaches.

In our analysis, we have not interrogated the data between different skills. We can see that confidence was increased overall through the blended route, and further analysis might shed light why learners increased their confidence to help for some skills but not others. Similarly, further interrogation of the knowledge data, including how long blended learners spent on each skill in their own time, ahead of the face to face time, could tell us more about the optimal blend for different skills, and we encourage further exploration of this aspect by other researchers.
Blended learning as a general approach to first aid education could result in shorter face-to-face sessions, which may appeal to learners or sponsors of courses (i.e., employers). Shorter face-to-face components could also offer cost savings to training organizations and sponsors in terms of room hire costs and educator hours. Blended learning within a comprehensive course offering allows learners to choose their preferred modality. Therefore, the benefits of developing elearning tools and a competent educator workforce offers training organizations opportunities to improve offerings.

\section{Limitations}

Our sample was limited to the availability of employees to participate in the capacity of the courses offered by the employer, therefore not a random sample of the population, and not powered to demonstrate statistical significance. The voluntary method of participant recruitment could limit the value of the findings as staff with more time on their hands or with a motivation to learn first aid might have been more likely to volunteer to participate. The population of office workers with experience of e-learning may also limit generalization of these results.

The inability to make a sub-analysis of time spent in the e-learning tool also limits the assessment of which elements may have contributed to outcomes. Similarly, being able to have observations between educators and learners at different locations would allow for future understanding of their role in developing outcomes. Limited time and access to learners also led to a shortened evaluation form and demographics that inhibited sub-group analysis (e.g., learner diversity or previous first aid training).

Learners in the blended cohort completed the evaluation form three times, whereas the face-to-face cohort only completed it twice. It is possible that our approach of test and re-test using the same evaluation questions introduces a bias from the repetition of questions which we have not accounted for. Our approach aimed to identify if there was improvement between phases of the study, but this could be due to familiarity with the evaluation form, particularly for the blended cohort. 
Final composite scores may be inflated where unanswered questions were due to the participant lacking knowledge or if illegible answers were incorrect.

\section{Conclusion}

Through this study we have found evidence to support first aid learning which applies e-learning followed by face-to-face learning being comparable in terms of educational effectiveness to face-to-face only facilitated learning. We have validated an approach described in literature, and one that is in congruence with the Chain of Survival Behaviour. This is an important finding as it should encourage curriculum designers and educators to explore the benefits of mixed learning modalities to suit different learner styles and diversity, educator capacity, and potential cost-effectiveness.

\section{Acknowledgements}

The British Red Cross is grateful to Philips ${ }^{\text {TM }}$ for their support of this study including provision of employees as participants, training rooms, administration support in communicating with learners, and creative insight on developing the e-learning tool. We are also grateful to BRC trainer Andrew Farrar and his team, and to others in the British Red Cross First Aid Education team for their support and expertise.

\section{Conflict of Interest}

All the authors were employed by the British Red Cross at the time of the study, although no COI is declared as no financial gain was made over and above their usual employment.

\section{Corresponding Author}

Emily Oliver, eoliver@redcross.org.uk

\section{References}

British Red Cross. (2014). BRC Everyday First Aid, London, UK: British Red Cross.

Chumley-Jones H.S., Dobbie A., \& Alford C.L. (2002). Web-based learning: sound educational method or hype? A review of the evaluation literature. Academic Medicine, 77(10), 86-93.

De Vries. W., Turner, N.M., Monsieurs. K.G., Bierens, J.J.L.M., \& Koster R.W. (2010). Comparison of instructor-led automated external defibrillation training and three alternative DVD-based training methods. Resuscitation, 84, 1004-1009.

Dikshit, J., Garg, S., \& Panda, S. (2013). Pedagogic effectiveness of print, interactive multimedia, and online resources: A case study of IGNOU. International Journal of Instruction, 6(2), 193-210.

Einspruch, E.L., Lynch, B., Aufderheide, T.P., Nichol, G., \& Becker, L. (2007). Retention of CPR skills learned in a traditional AHA Heartsaver course versus 30-min video self-training: A controlled randomized study. Resuscitation, 74, 476-486.

Ellio, M. (2013). White paper: Blended learning. Retrieved from: www.epic.co.uk/content/resources/white papers/blended.htm.

Glaser, R. (1991). The maturing of the relationship between the science of learning and cognition and educational practice. Learning and Instruction, 1, 129-44. 
Golchaia, B., Nazaria, N., Hassania, F., \& Bahadori, M.H. (2012). Computer-based E-teaching (virtual Medical Teaching) or traditional teaching: A comparison between Medical and Dentistry students. Social and Behavioural Sciences, 47, 2080 - 2083.

Hudson, J. N. (2004). Computer-aided learning in the real world of medical education: does the quality of interaction with the computer affect student learning? Medical Education, 38, 887-895.

IFRC Guidelines (2016). International first aid and resuscitation guidelines. Geneva: International Federation of the Red Cross.

Johnson, L. (2003). Elusive Vision: Challenges Impeding the Learning Object Economy. White paper. Retrieved from http://www.nmc.org/pdf/Elusive Vision.pdf.

Modell, H.I. (1996). Preparing students to participate in an active learning environment. Advanced Phycological Education, 5, 69-77.

Mpotos, N., Yde, L., Calle, P., Deschepper, E., Valcke, M., Peersman, W., Herregods, L., \& Monsieurs, K. (2013) Retraining basic life support skills using video, voice feedback or both: A randomized controlled skills. Resuscitation, 84, 72-77.

Oliver, E., Cooper, J., \& McKinney, D. (2013) Can training encourage individuals' propensity to act in an emergency situation? A pilot study. Emergency Medicine Journal, 1, 1-3.

Pellegrino, J. L., Oliver, E., Orkin, A., Marentette, D., \& Snobelen, P. J. (2017). A call for revolution in first aid education. International Journal of First Aid Education, 1(1). https://doi.org/10.21038/ijfa.2017.0001

Perkins, G.D., Fullerton, J.N., Davis-Gomez, N., Davies, R.P., Baldock, C., Stevens, H., Bullock, I., \& Lockey, A.S. (2010). The effect of pre-course e-learning prior to advanced life support training: A randomised controlled trial. Ressuscitation, 81, 877-881.

Perkins, G.D., Kimani, P.K., Bullock, I., Clutton-Brock, T., Davies, R.P., Gale, M., Lam, J., Lockey, A., \& Stallard, N. (2012). Improving the efficiency of advanced life support training: A randomized, controlled trial. Annals of Internal Medicine, 157, 19-28.

Ruiz, J. G., Mintzer M. J., \& Leipzig R, M. (2006). The Impact of E-Learning in Medical Education. Academic Medicine, 81(3), 207-212.

Smith, R.(2004). Guidelines for Authors of Learning Objects. Retreived from: http://www.nmc.org/guidelines/NMC/20LO/20Guidelines.pdf.

Søreide, E., Morrison, L., Hillman, K., Monsieurs, K., Sunde, K., Zideman, D., Eisenberg, M., Sterz, F., Nadkarni, V.M., \& Nolan, J.P. (2013). The formula for survival in resuscitation. Resuscitation, 84, 1487-1493.

Taplin, J., \& McConigley, R. (2015). Advanced life support (ALS) instructors experience of ALS education in Western Australia: A qualitative exploratory research study. Nurse Education Today, 35, 556561. 
Thorne, C.J., Lockey, A.S., Bullock, I., Hampshire, S., Begum-Ali, S., \& Perkins, G.D. (2015). E-Learning in advanced life support: an evaluation by the Resuscitation Council (UK). Resuscitation, 90, 79-84.

Walsh, K. (2005). Blended Learning. British Medical Journal, 330, 829.

Appendix 1: Difference in change of knowledge by skill and learner group

\begin{tabular}{|c|c|c|c|c|c|c|c|}
\hline \multirow[b]{2}{*}{ First aid area } & \multicolumn{3}{|c|}{ Face-to-face $(n=54)$} & \multicolumn{4}{|c|}{ Blended $(n=46)$} \\
\hline & $\begin{array}{c}\text { T1 } \\
\text { Pass rate }\end{array}$ & $\begin{array}{c}\text { T3 } \\
\text { Pass rate }\end{array}$ & Change & $\begin{array}{c}\mathrm{T} 1 \\
\text { Pass rate }\end{array}$ & $\begin{array}{c}\text { T3 } \\
\text { Pass rate }\end{array}$ & Change & $p$-value \\
\hline $\begin{array}{l}\text { Allergic } \\
\text { reaction }\end{array}$ & $18.6 \%$ & $58.5 \%$ & $39.9 \%$ & $10.9 \%$ & $31.1 \%$ & $20.2 \%$ & $0.033^{*}$ \\
\hline Bleeding & $43.4 \%$ & $92.6 \%$ & $49.2 \%$ & $41.3 \%$ & $100.0 \%$ & $58.7 \%$ & 0.061 \\
\hline Broken bones & $17.8 \%$ & $82.7 \%$ & $64.9 \%$ & $23.9 \%$ & $80.0 \%$ & $56.1 \%$ & 0.772 \\
\hline Burn & $7.5 \%$ & $69.2 \%$ & $61.7 \%$ & $17.4 \%$ & $88.9 \%$ & $71.5 \%$ & $0.029 *$ \\
\hline Choking & $47.7 \%$ & $96.3 \%$ & $48.6 \%$ & $24.4 \%$ & $97.8 \%$ & $73.4 \%$ & 0.679 \\
\hline $\begin{array}{l}\text { Diabetic } \\
\text { emergency }\end{array}$ & $52.0 \%$ & $98.1 \%$ & $46.1 \%$ & $56.1 \%$ & $97.8 \%$ & $41.7 \%$ & 0.897 \\
\hline Head injury & $5.9 \%$ & $81.1 \%$ & $75.2 \%$ & $10.9 \%$ & $65.2 \%$ & $54.3 \%$ & 0.106 \\
\hline Heart attack & $43.1 \%$ & $88.7 \%$ & $45.6 \%$ & $43.5 \%$ & $80.0 \%$ & $36.5 \%$ & 0.259 \\
\hline Seizure & $31.0 \%$ & $88.0 \%$ & $57.0 \%$ & $47.8 \%$ & $86.4 \%$ & $38.6 \%$ & 0.813 \\
\hline $\begin{array}{l}\text { Strains and } \\
\text { sprains }\end{array}$ & $23.8 \%$ & $77.4 \%$ & $53.6 \%$ & $28.3 \%$ & $84.4 \%$ & $56.1 \%$ & 0.379 \\
\hline Stroke & $86.0 \%$ & $90.7 \%$ & $4.7 \%$ & $68.9 \%$ & $91.1 \%$ & $22.2 \%$ & 0.916 \\
\hline $\begin{array}{l}\text { Unconscious \& } \\
\text { breathing }\end{array}$ & $54.0 \%$ & $94.2 \%$ & $40.2 \%$ & $65.2 \%$ & $93.3 \%$ & $28.1 \%$ & 0.856 \\
\hline $\begin{array}{l}\text { Unconscious \& } \\
\text { not breathing }\end{array}$ & $19.2 \%$ & $92.6 \%$ & $73.4 \%$ & $32.6 \%$ & $91.3 \%$ & $58.7 \%$ & 0.837 \\
\hline
\end{tabular}

* Mann Whitney $U$ analysis for statistical significance at $p \leq .05$ for amount of change between independent samples. 
Original Research

Appendix 2: Change in self-reported confidence by skill and learner group

\begin{tabular}{|c|c|c|c|c|c|c|c|}
\hline \multirow[b]{2}{*}{ First aid area } & \multicolumn{3}{|c|}{ Face-to-face $(n=54)$} & \multicolumn{4}{|c|}{ Blended $(n=46)$} \\
\hline & $\begin{array}{l}\text { T1 Median } \\
\text { (IQR) }\end{array}$ & $\begin{array}{l}\text { T3 Median } \\
\text { (IQR) }\end{array}$ & Change & $\begin{array}{c}\text { T1 } \\
\text { Median } \\
\text { (IQR) }\end{array}$ & $\begin{array}{l}\text { T3 Median } \\
\text { (IQR) }\end{array}$ & Change & $\mathrm{p}$-value \\
\hline Allergic reaction & $2.0(5.0)$ & $8.0(3.0)$ & 6.0 & $3.0(5.0)$ & $9.0(2.0)$ & 6.0 & $0.007^{*}$ \\
\hline Bleeding & $6.0(4.0)$ & $9.0(2.0)$ & 3.0 & $5.0(5.0)$ & $10.0(2.0)$ & 5.0 & 0.138 \\
\hline Broken bones & $3.0(5.0)$ & $8.5(3.0)$ & 5.5 & $4.0(5.0)$ & $9.0(2.0)$ & 5.0 & $0.042 *$ \\
\hline Burn & $5.0(4.0)$ & $9.0(2.0)$ & 4.0 & $6.0(5.0)$ & $10.0(1.0)$ & 4.0 & 0.086 \\
\hline Choking & $3.0(4.0)$ & $8.0(2.0)$ & 5.0 & $4.0(5.0)$ & $10.0(2.0)$ & 6.0 & $0.001 *$ \\
\hline Diabetic emergen & $3.0(5.0)$ & $9.0(1.0)$ & 6.0 & $3.0(4.0)$ & $10.0(2.0)$ & 7.0 & $0.002 *$ \\
\hline Head injury & $3.0(3.0)$ & $8.0(2.0)$ & 5.0 & $3.0(3.0)$ & $9.0(2.0)$ & 6.0 & $0.031 *$ \\
\hline Heart Attack & $3.0(4.0)$ & $8.0(2.0)$ & 5.0 & $3.0(3.0)$ & $9.0(2.0)$ & 6.0 & $0.022^{*}$ \\
\hline Seizure & $2.0(4.0)$ & $9.0(3.0)$ & 7.0 & $2.0(5.0)$ & $10.0(2.0)$ & 8.0 & 0.145 \\
\hline $\begin{array}{l}\text { Strains and } \\
\text { sprains }\end{array}$ & $4.0(4.0)$ & $9.0(3.0)$ & 5.0 & $4.0(6.0)$ & $10.0(2.0)$ & 6.0 & $0.050 *$ \\
\hline Stroke & $4.0(5.0)$ & $9.0(3.0)$ & 5.0 & $4.0(4.0)$ & $10.0(2.0)$ & 6.0 & $0.034^{*}$ \\
\hline $\begin{array}{l}\text { Unconscious \& } \\
\text { breathing }\end{array}$ & $3.0(4.0)$ & $9.0(2.0)$ & 6.0 & $4.0(5.0)$ & $10.0(2.0)$ & 6.0 & 0.109 \\
\hline $\begin{array}{l}\text { Unconscious \& } \\
\text { not breathing }\end{array}$ & $3.0(4.0)$ & $8.0(8.0)$ & 5.0 & $3.0(3.0)$ & $9.0(1.0)$ & 6.0 & $0.045^{*}$ \\
\hline
\end{tabular}

* Mann Whitney $U$ analysis for statistical significance at $p \leq .05$ for amount of change between independent samples. 